\section{Knowledge, attitude and practice of contraceptive use among female students of Dilla secondary and preparatory school, Dilla town, South Ethiopia, 2014}

\author{
Samuel Kusheta Katama, \\ Desalegn Tsegaw Hibstu² \\ 'Department of Health Extension, \\ Hossana College of Health sciences, \\ Hossana; 'Department of Reproductive \\ Health, Hawassa University, Hawassa, \\ Ethiopia
}

\section{Abstract}

Family planning is known not only as a fundamental intervention for improving the health of women but also as a human right. The aim of this study was to assess the current knowledge, attitude and practice of contraceptive use among female students in Dilla secondary and preparatory school, Dilla, South Ethiopia, 2014. A cross sectional study was conducted among 288 female students in Dilla secondary and preparatory school, south Ethiopia, June 1929/2014. A simple random sampling technique was used to select the study subjects. The data was collected using a self-administered structured questionnaire. The data was analyzed by SPSS 20. Chi-square test was used to identify associated factors. A total of 263 female students were involved in this study, of which 249 (94.7\%) had good knowledge about contraception. The three most frequently identified methods were injectable form (83.9\%), oral contraceptive pills (72.7\%) and condom (48.6\%). A total of $15.7 \%$ respondents ever used contraceptive. Among the users, 56.4\% used oral contraceptive pills, and 23.1 and $10.2 \%$ used injectable form and condom, respectively. In spite of the fact that most respondents had good knowledge of contraception, their attitude and practice was low. Emphasis needs to be given on disseminating health information concerning the attitude and practice of contraceptive method.

\section{Introduction}

Family planning is known not only as a fundamental intervention for improving the health of women but also as a human right. The basis for action in family planning must enable couples and individuals to decide freely and responsibly the number and spacing of their children. ${ }^{1}$ Ethiopia is the second most populous country in Africa. Its population has increased nearly seven times from 11.8 million at the beginning of the $20^{\text {th }}$ century to about 80 million today. The total fertility rate of Ethiopia is 4.8 with estimated population growth rate is $2.7 \%$ per year, contraceptive prevalence $29 \%{ }^{2}$

In Ethiopia, unwanted pregnancy is a serious issue where more than $60 \%$ of the pregnancies in adolescents are unwanted resulting from unprotected sexual intercourse which is an alarming figure, and most of these pregnancies particularly in adolescents end up with unsafe abortion. ${ }^{3}$ An African woman's chance of dying from pregnancy related causes: obstructed labor, postpartum hemorrhage, pregnancy induced hypertension, post partum infection and unsafe abortion average 870 per 100,000 live births in contrast to developed countries which is 27 per 100,000 live births. ${ }^{4}$

One of the big challenges to the reproductive health of young adults in developing countries like Ethiopia is unintended pregnancy. As a result of the decreasing age of menarche and onset of sexual activity, youths are facing early unplanned and unprotected sexual intercourse leaving them vulnerable to unwanted pregnancies and invariable abortions. ${ }^{5}$ About 3.7 million unsafe abortions are performed each year in sub-Saharan Africa and about 23,000 African women die from its complication. East African women face the highest life time risk of maternal death of 1 in 12 compared with 1 in 3700 women in North America. ${ }^{6}$

Low-income countries are confronted with a vicious cycle: efforts to improve living standards and to alleviate poverty are overwhelmed by the need to provide basic services and jobs for the growing number of people. Provision of family planning service has become the intervention of choice to stabilize demographic explosion. ${ }^{7}$

There are many causes for the low contraceptive prevalence rate that needs to be explored. It will be easy to design implementation methods for the alleviation of consequences of not using contraceptives if the reasons are identified. The problem is more acute among teenagers due to various reasons. A study done on knowledge, attitude and practice of family planning methods and other reproductive health diseases including HIV/AIDS among school adolescents in seven towns of Ethiopia showed that most of the sexually active school adolescents did not use contraception. ${ }^{8}$ This paper attempts to assess the current knowledge, attitude, and practice of contraception among female students of Dilla secondary and preparatory school.
Correspondence: Desalegn Tsegaw Hibstu, Department of Reproductive Health, Hawassa University, Hawassa, Ethiopia.

E-mail: samkush2012@yahoo.com, desuethiopia@ yahoo.com

Key words: Family planning; Contraceptive use; Dilla; Ethiopia.

Conflict of interest: the authors declare no potential conflict of interest.

Contributions: SKK and DTH participated from the conception to the end of this manuscript.

Received for publication: 11 December 2015. Accepted for publication: 16 January 2016.

This work is licensed under a Creative Commons Attribution 4.0 License (by-nc 4.0).

(C) Copyright S.K. Katama and D.T. Hibstu 2016 Licensee PAGEPress, Italy

Healthcare in Low-resource Settings 2016; 4:5680 doi:10.4081/hls.2016.5680

\section{Materials and Methods}

\section{Study area and period}

The study was conducted in Dilla town, the capital of Gedeo zone [Southern, Nation Nationalities and People's Regional state (SNNPR)]. The town is located at a distance of 359 KM from Addis Ababa, capital city of Ethiopia and $90 \mathrm{KM}$ from Hawassa, the capital city of SNNPR, Ethiopia. Cross sectional study design was used from June 19-29/2014.

\section{Population}

The source population was made up of all Dilla secondary and preparatory high school students enrolled in the year 2014 and students who were absent and seriously sick students on the day of data collection were excluded in this study. The study population included all randomly selected students in Dilla secondary and preparatory high school in the year 2014 .

\section{Study variables}

The study variables were developed based on the different literature reviews and from previous studies. The outcome variables are: knowledge of contraceptive use, attitude towards contraceptive use, and practice of contraceptive use. The personal variables are: age, ethnicity, religions, marital status, educational level, reasons for not using contraception, and source of information. In this paper knowledge of contraception was defined as awareness of women about family planning methods or having information about contraception. The study subjects 
needed to answer $>70 \%$ of the question on knowledge section to be classified as knowledgeable, practice is defined as the overt behavior, habit or customs of women using contraception. The study subject were to answer the $1^{\text {st }}$ question yes on the practice section and then to specify the type to be classified as good or poor practice. The study subjects were considered to have good attitude if they gave appropriate answers for $>70 \%$ of the questions on attitude section.

\section{Sample size determination and sampling procedure}

The sample size was determined using single population proportion formula:

$$
\mathrm{n}=\mathrm{z}_{/ 2}^{2}(\mathrm{pq}) / \mathrm{d}^{2}
$$

where $\mathrm{n}=$ sample size, $\mathrm{Z}=$ reliability coefficient with 95\%confidence interval, $\mathrm{p}=$ prevalence of contraceptive use (29\%)[2], q=1-p, d= Standard error allowed taken as 5\%. And the final sample size was 288 with $10 \%$ nonresponse rate after using the sample size correction formula.

To get the representative sample stratification was done by grades (grade nine, ten, eleven and twelve). Based on this the strata was done by considering number of sections from each grade. The final sample size was obtained and proportionally allocated for each section. The total samples were taken from the sampling frame using simple random sampling technique available from their identification number using computer generated random number from each class. The selected students were gathered in a room and provided with a self-administered questionnaire that was filled out in the same room.

\section{Data collection and quality control procedures}

Pre-tested and self-administered structured questionnaires were used. Two day training was given to data collection facilitators. Two principal investigators supervised the overall data collection and checked the completeness of the questionnaire for consistency. The questionnaire was prepared in the English language and translated to Amharic (local language) and translated back to English. After data collection, questionnaires were reviewed and checked for completeness and relevance by the principal investigators.

\section{Data processing and analysis}

After data collection, each questionnaire was checked for completeness and code was given before data entry. Data was cleaned and entered into computer by using Epi Info version 3.5.3 and the analysis was done using SPSS version 20.0. Data was edited and cleaned before data analysis. Descriptive statistics and chi-square tests were used and significance of tests were decided at $\mathrm{P}<0.05$.

\section{Ethical consideration}

Ethical clearance was obtained from the ethical clearance board of Dilla University, College of Health Sciences. All participants' right to self-determination was respected. The study participants were informed about the purpose of the study and informed verbal consent was secured.

\section{Results}

\section{Socio-demographic characteristics}

A total of 263 female students participated in the study with a response rate of $91.3 \%$. Age of the study subjects ranged from 14-22 years with median age of 19. Among the studied female students, 170 (64.6\%) were Gedeo followed by Amahara 41 (15.6\%) by ethnicity. Two hundred forty eight $(94.3 \%)$ of the respondents were single and 119 (45.2\%) of the study participants were from grade nine (Table 1).

\section{Contraceptive knowledge}

Of the students, 249 (94.7\%) had heard about contraceptives. All of them correctly identified at least one contraceptive method. The three most frequently identified contraceptive methods were injectable form 209 (83.9\%) followed by oral contraceptive pills 181 (72.7\%) and condom 121 (48.6\%) (Table 2). The sources of contraceptive knowledge were television, $104(41.8 \%)$, radio $54(21.7 \%)$ and teachers 49 (19.7\%) (Table 3). It was found that $191(76.7 \%)$ said that contraceptives are used to prevent unwanted pregnancy, 209 (83.9\%) to limit or space childbirth, and 48 (19.3\%) answered to prevent sexually transmitted diseases (Table 4).

\section{Attitude towards contraception}

One hundred seventy eight (71.5\%) students had a favorable attitude towards contraceptives. Among them, 111 (63.4\%) are orthodox christians having positive attitude, 56 (31.5\%) protestant, 6 (3.4\%) catholic and $5(2.8 \%)$ of muslim students have positive attitude towards contraceptive (Table 5).

\section{Contraceptive practice}

A total of 39 (15.7\%) respondents had ever used contraceptive method. Of 39 students who practiced contraceptive 26 (66.7\%) were unmarried and 13 (33.3\%) were married. Among those that practiced contraceptives 19 (48.7\%) were orthodox, 15 (38.5\%) were protestant, 3 (7.7\%) were muslim, and 2 (5.1\%) were catholic students. The commonly used contraceptive method was pills, 22 (56.4\%) followed by injectable, 9 (23.1\%) and condom 4 (10.2\%) (Table 6).

\section{Discussion}

Family planning is defined by WHO as a way of thinking and living that is adopted voluntarily, upon the basis of knowledge, attitudes and responsible decisions by individuals and couples, in order to promote the health and welfare of family groups and thus contribute effectively to the social development of a country.

This study showed about $94.7 \%$ of respondents had knowledge of contraceptive method. This finding was in agreement with the report-

Table 1. Socio-demographic characteristics of female students of Dilla secondary and preparatory school, Dilla town, South Ethiopia, July 2014.

\begin{tabular}{lcl} 
Variables & n & $\%$ \\
Age (years) & & \\
14-16 & 21 & 8.0 \\
$17-19$ & 196 & 74.5 \\
$20-22$ & 46 & 17.5 \\
Religion & & \\
Orthodox & 172 & 65.4 \\
Protestant & 75 & 28.5 \\
Muslim & 9 & 3.4 \\
Catholic & 7 & 2.7 \\
\hline Ethnicity & & \\
Gedeo & 170 & 64.6 \\
Amhara & 41 & 15.6 \\
Oromo & 19 & 7.2 \\
Tigre & 7 & 2.7 \\
Sidama & 12 & 4.6 \\
Gurage & 15 & 5.3 \\
Marital status & & \\
Single & 248 & 94.3 \\
Married & 15 & 5.7 \\
\hline Grade & & \\
$9^{\text {th }}$ & 119 & 45.2 \\
$10^{\text {th }}$ & 42 & 16.0 \\
$11^{\text {th }}$ & 75 & 28.5 \\
$12^{\text {th }}$ & 27 & 10.3 \\
\hline
\end{tabular}

Table 2. Knowledge of contraceptive methods among female students of Dilla secondary and preparatory school, Dilla town, South Ethiopia, July 2014.

\begin{tabular}{lcc} 
Variables & n & $\%$ \\
Heard contraceptive & & \\
$\quad$ Yes & 249 & 94.7 \\
No & 14 & 5.3 \\
Method known & & \\
Injectable & 209 & 83.9 \\
Oral pills & 181 & 72.7 \\
Condom & 121 & 48.6 \\
Calendar (rhythm) & 99 & 39.8 \\
Coitus interrupts & 94 & 37.7 \\
Loop (IUCD) & 83 & 33.3 \\
Norplant@ & 49 & 19.7 \\
Tubal ligation & 71 & 28.5 \\
Breast feeding & 47 & 18.9 \\
\hline
\end{tabular}

IUCD, intrauterine contraceptive device. 
ed contraceptive knowledge level of adolescents to be $93-98 \%{ }^{9-12}$ Still, this finding was higher than reports of students from other urban centers of the country where contraceptive knowledge level varies from $54 \%$ in Harar $^{13}$ to $75-83 \%$ in North Gondar. ${ }^{14}$ This magnitude was also comparable with the level of adolescents' contraceptive knowledge in Asia, North Africa, the Caribbean and Latin America, where the level of adolescents' knowledge on contraception was above $90 \%{ }^{15}$ This might be due to the better information exposure and communication that school adolescents now have and influence of mass media.

Perhaps, it could be due to the fact that the most widely available method of family planning is oral contraceptive pills, the most familiar method obtained in this paper was oral contraceptive pill, which was congruent with other studies. About seventy percent of study subjects had heard about emergency contraception. A study conducted in Nigeria and Addis Ababa University showed that 58 and $43.3 \%$ knew about emergency contraception, respectively. ${ }^{16,17}$ The result of this study was higher; the difference could be due to the difference in the population studied and time interval between the studies. Contraceptive use in this study was $15.7 \%$. A research done in North Gondar showed that contraceptive use was $30.7 \%,{ }^{18}$ while a study done in Harar was $20 \% .^{13}$ The possible reason for this difference could be poor attitude towards contraceptive use in the present study because of religious and cultural reason, and variation in the population studied.

The major source of information on contraception in this study was television (41.8\%) while it was $23.8 \%$ in a study done in North Gondar. ${ }^{18}$ This difference might be due to increasing number of televisions per household with increasing emphasis by the government through different attractive announcements and programs on television. In this study, it was observed that pharmacy/drug vender was the main source of contraceptive method accounting for $87.2 \%$ (Figure 1). A study done in Jimma urban population showed 98.96\% from clinic and pharmacy. ${ }^{16}$ Among those who did not use any method of contraceptive in this study, $46.5 \%$ were not using for cultural reason, and $27.6 \%$ for religious reason and $23.7 \%$ because of lack of knowledge (Figure 2). A study done in north Gondar showed that majority of non-users did not use because of lack of knowledge or access to service. $^{18}$ This could be the difference in the population studied and changes in the study period.

\section{Conclusions}

This study showed that most of the students
Table 3. Source of contraceptive knowledge in Dilla secondary and preparatory school female students, Dilla town, South Ethiopia July, 2014.

\begin{tabular}{lcc}
$\begin{array}{l}\text { Source } \\
\text { of knowledge }\end{array}$ & $\begin{array}{c}\mathrm{n} \\
\text { (tot=249) }\end{array}$ & $\%$ \\
TV & 104 & 41.8 \\
Radio & 54 & 21.7 \\
\hline Teacher & 49 & 19.7 \\
Friends & 40 & 16.1 \\
\hline Health worker & 24 & 9.6 \\
Books & 18 & 7.2 \\
\hline Magazines & 15 & 6 \\
\hline
\end{tabular}

Table 4. Distribution of female students in Dilla secondary and preparatory school by their knowledge about importance of contraception.

\begin{tabular}{lcc}
\hline Importance of contraception & n & $\%$ \\
Prevent unwanted pregnancy & 191 & 76.7 \\
Prevent STD & 48 & 19.3 \\
\hline Limit/space child birth & 209 & 83.9 \\
Treat menstruation pain & 28 & 11.2 \\
\hline Prevent abortion complications & 12 & 4.8 \\
\hline STD, sexually transmitted disease. & &
\end{tabular}

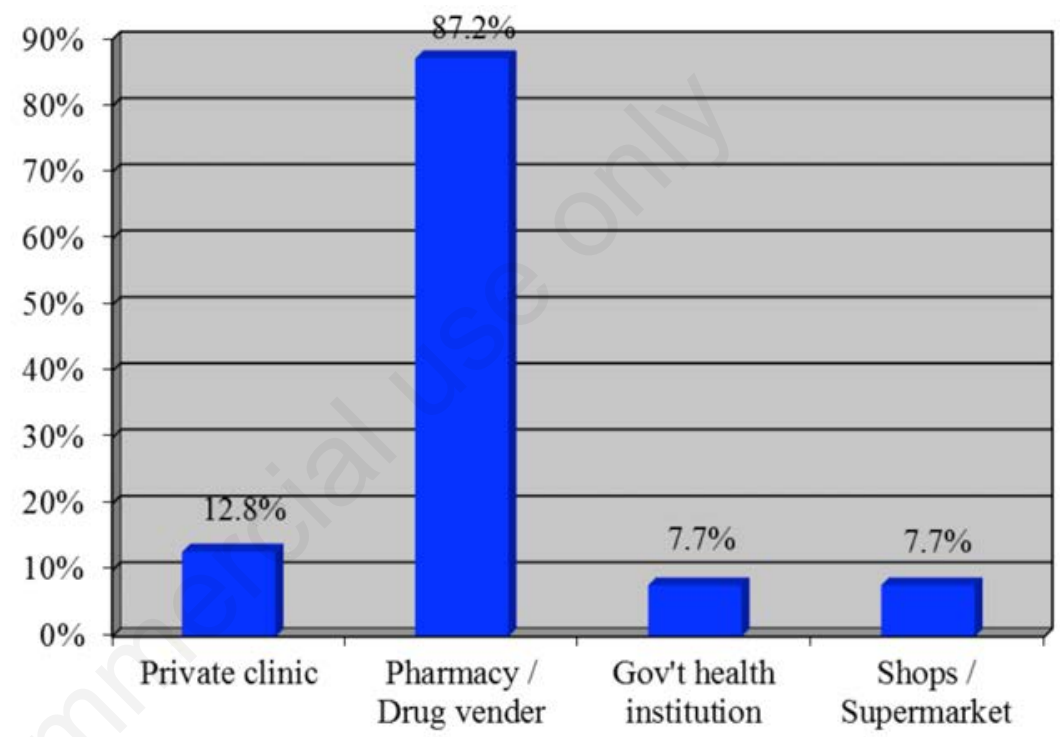

Figure 1. Distribution of respondents by source of contraceptive used among Dilla secondary and preparatory school, Dilla town, South Ethiopia, July 2014.

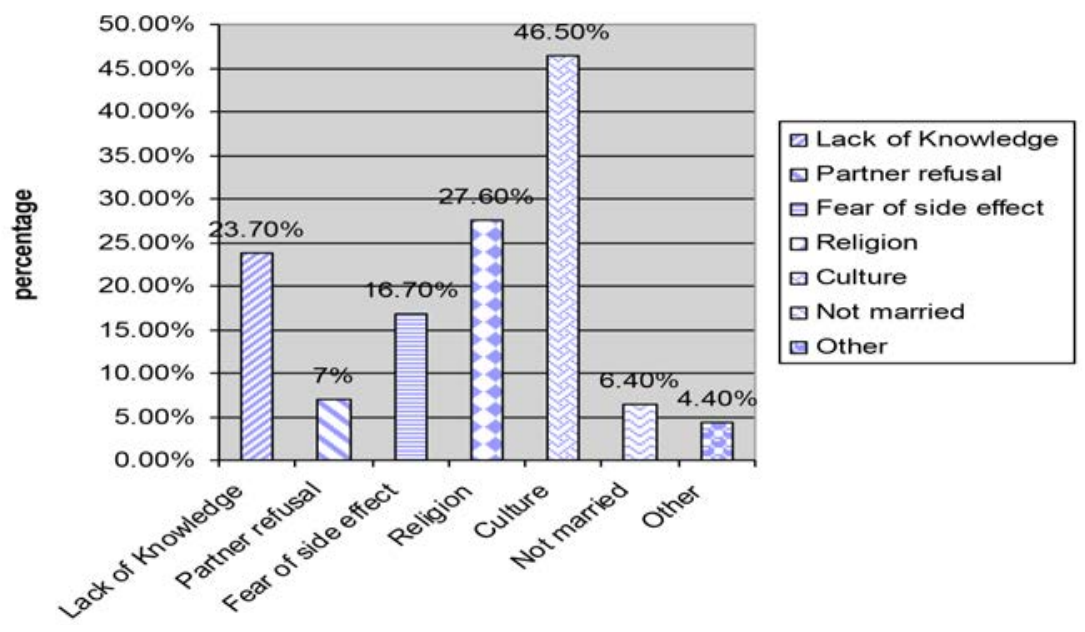

Figure 2. Distribution of respondents by their reason for not using contraceptive in Dilla secondary and preparatory school, Dilla town, South Ethiopia, July 2014. 
Table 5. Contraceptive knowledge, attitude and practice in different religious groups of Dilla secondary and preparatory school female students, Dilla town, South Ethiopia, July 2014.

\begin{tabular}{|c|c|c|c|c|c|c|}
\hline \multirow{2}{*}{ Religion } & \multicolumn{2}{|c|}{ Knowledge } & \multicolumn{2}{|c|}{ Attitude } & \multicolumn{2}{|c|}{ Practice } \\
\hline & $\begin{array}{l}\text { Yes } \\
\text { n (\%) }\end{array}$ & $\begin{array}{c}\text { No } \\
\text { n (\%) }\end{array}$ & $\begin{array}{c}\text { Yes } \\
\text { n (\%) }\end{array}$ & $\begin{array}{c}\text { No } \\
\text { n (\%) }\end{array}$ & $\begin{array}{c}\text { Yes } \\
\text { n (\%) }\end{array}$ & $\begin{array}{c}\text { No } \\
\text { n (\%) }\end{array}$ \\
\hline Orthodox & $162(94.2)$ & $10(5.8)$ & $111(64.5)$ & $61(35.5)$ & $19(11.0)$ & $153(89.0)$ \\
\hline Protestant & $73(97.3)$ & $2(2.7)$ & $56(74.7)$ & $19(25.3)$ & $15(20.0)$ & $60(80.0)$ \\
\hline Muslim & $9(100)$ & $0(0.0)$ & $5(55.6)$ & $4(44.4)$ & $3(33.3)$ & $6(66.7)$ \\
\hline Catholic & $5(71.4)$ & $2(28.6)$ & $6(85.7)$ & $1(14.3)$ & $2(28.6)$ & $5(71.4)$ \\
\hline Significant test & \multicolumn{2}{|c|}{$\mathrm{X}^{2}=8.32 ; \mathrm{P}=0.04$} & \multicolumn{2}{|c|}{$\mathrm{X}^{2}=13.66 ; \mathrm{P}=0.034$} & \multicolumn{2}{|c|}{$\mathrm{X}^{2}=3.19 ; \mathrm{P}=0.36$} \\
\hline
\end{tabular}

Table 6. Contraceptive usage among Dilla secondary and preparatory school female students, Dilla town, South Ethiopia, July 2014.

\begin{tabular}{llcc} 
Practice & & n & $\%$ \\
Ever used & Yes & 39 & 15.7 \\
& No & 210 & 84.3 \\
Type used & Oral pills & 22 & 56.4 \\
& Injectable & 9 & 23.1 \\
& Condom & 4 & 10.2 \\
& Calendar (rhythm) & 2 & 5.1 \\
& Coitus interrupts & 1 & 2.6 \\
& Norplant $^{\circledR}$ & 1 & 2.6 \\
\hline
\end{tabular}

had knowledge of contraception. Predominant methods known by students were injectable, oral contraceptive pills and condom, respectively but the number one method used by students was oral contraceptive pills. Older adolescents (age 18-22 years) and higher grades $\left(11^{\text {th }}\right.$ and $12^{\text {th }}$ students) ever used contraceptive methods than younger ones and lower grades (Grade 9 and 10). Television, radio, and teachers were found to be the most important source of information for promoting utilization of contraceptives. Marital status was found to be associated with higher rates of contraceptive use. Among the non-users, the majority of respondents did not practice for religions and cultural reason and lack of knowledge. Most women have good attitude towards contraceptives. Information, education and communication activities regarding utilization of modern contraceptive methods among adolescents and their importance should be strengthened by the Ministry of Health through mass media messages and encouraging school health programs. Including family planning in the educational curriculum both at elementary and secondary schools needs emphasis, so that knowledge and practice of modern contraception can be utilized early at least for those who are not out of school. Community health education programs regarding culture need to be planned and carried out to the community at large. Encouraging mini media programs and establishing reproductive health clubs should be promoted by school officials.

\section{References}

1. WHO. Improving access to quality cares in family planning. Geneva, Switzerland: WHO; 1996.

2. Central Statistical Agency-ICF International. Ethiopia demographic and health survey. Addis Ababa, Ethiopia, and Calverton, MA, USA: Central Statistical Agency and ICF International; 2012.

3. Tilahun D, Assefa T, Belachew T. Knowledge, attitude and practice of emergency contraceptive among Adama University female student. Ethiopian J Reprod Health 2010;20:195-202.

4. Ethiopian Population. Ethiopian linkage between population and economy, 2007. Available from: http://www.ethiopianpopulation.com

5. Park K. Textbook of preventive and social medicine. 22th ed. Jabalpur: Banarsidas Bhanot Publ.; 2013.

6. World Bank. Effective, family planning programs. Washington, DC: Wordl Bank; 1993.

7. WHO. Community based distribution of contraceptive. A guide for program manager. Geneva, Switzerland: WHO; 1995.

8. Birhan Research \& Development Consultancy. Ethiopia: knowledge, attitudes and practices in family planning. Results from September 2004 survey of Amhara, Oromia, SNNPR and Tigray regions. Available from:
pdf.usaid.gov/pdf_docs/Pnadp662.pdf

9. Aklilu K, Hailom B. Youth reproductive health in Ethiopia. Ethiopia demograhic and health survey. Calverton, MA: ORC Marco; 2002.

10. Berhane F. Health problems and service preferences of school adolescents in Addis Ababa with emphasis on reproductive health. Department of Community Health: Addis Ababa, Ethiopia; 2000.

11. Tilahun T, Coene G, Luchters S, et al. Family planning knowledge, attitude and practice among married couples in Jimma zone, Ethiopia. PLoS One 2013;8:e61335.

12. Kasahun S. Sexual behavior, contraceptive practice and knowledge of Aids of high school students in Addis Ababa. Addis Ababa: University of Addis Ababa; 1997.

13. Bisrat F. Knowledge, attitude and practice of contraceptive among high school students in Harar town, Eastern Ethiopia. Ethiopian J Health Dev 1994;32:151-60.

14. Kebede Y. Contraceptive prevalence and factors associated its usage in Gondar Town, North Ethiopia. Ethiopian J Health Dev 2000;14:32-9.

15. Sigh S, Kluif D. The likelihood of induced abortion among women hospitalized for abortion complication in four Latin American countries. Int Fam Plan Persp 1993;19:134-41.

16. Aziken ME, Okonta PI, Ande AB. Knowledge and perception of emergency contraception among female Nigerian undergraduates. Int Fam Plan Persp 2003;29:84-7.

17. Tamire W, Enquselassie F. Knowledge, attitude and practice on EC among female students at higher education, Addis Ababa, Ethiopia. Addis Ababa: University of Addis Ababa; 2005.

18. Shiferaw M. Determinants of contraceptive use in Jimma herbal population, south West Ethiopia. Addis Ababa: Family Guidance association of Ethiopia; 1990. 